\title{
Understanding prostate cancer cells metabolome: a spectroscopic approach
}

Francisco Santos ${ }^{a, b}$, Sandra Magalhães ${ }^{a}$, Magda Carvalho Henriques ${ }^{b}$, Beatriz Silvac, Isabel Valençac, Daniela Ribeiro ${ }^{c}$, Margarida Fardilha ${ }^{\mathrm{b}}$ and Alexandra Nunes ${ }^{\mathrm{a}}$

\footnotetext{
a iBiMED - Institute of Biomedicine, Department of Medical Sciences, University of Aveiro, Aveiro, Portugal

b Signal Transduction Laboratory, iBiMED - Institute of Biomedicine, Department of Medical Sciences, University of Aveiro, Aveiro, Portugal

c Organelle Dynamics in Infection and Disease Laboratory, iBiMED - Institute of Biomedicine, Department of Medical Sciences, University of Aveiro, Aveiro, Portugal
}

Corresponding author: Alexandra Nunes

iBiMED - Institute of Biomedicine, Department of Medical Sciences

University of Aveiro

Agra do Crasto, 3810-193, Aveiro, Portugal

alexandranunes@ua.pt

\begin{abstract}
Prostate cancer ( $\mathrm{PCa}$ ) is the second most common neoplasia in men. Because it is often diagnosed at a late stage, mortality rates remain high. Studying cancer metabolome, which reflects early changes that occur in cells, has gained relevance and may contribute to the identification of early diagnostic biomarkers and understanding tumor biology. Fourier-transform infrared (FTIR) spectroscopy is a metabolomics technique that probes the biochemical composition of the analyzed samples and allows to discriminate samples with distinct metabolic profiles, allowing the discrimination between cancerous and non-cancerous samples. In this study, FTIR spectra were acquired from PCa and normal prostate cell lines and analyzed by principal component analysis (PCA). Our results indicate a clear discrimination between the different cell lines, meaning that they exhibit distinct metabolic profiles. This discrimination can be attributed to an altered lipid metabolism (3000-2800 $\mathrm{cm}^{-1}, 1800-1700 \mathrm{~cm}^{-1}$ and 1500 $\left.1400 \mathrm{~cm}^{-1}\right)$ and changes in protein conformation $\left(1700-1600 \mathrm{~cm}^{-1}\right)$. These results suggest that studying cancer metabolome with FTIR spectroscopy not only allows the understanding of tumor metabolic behavior and may be useful to the development of new therapeutic targets.
\end{abstract}

Keywords: Prostate cancer, cell lines, metabolomics, FTIR, metabolic profile, principal component analysis 


\section{Introduction}

Worldwide, 1.1 million new cases of PCa were registered in 2012, 307,000 of which resulted in death. These figures place $\mathrm{PCa}$ as the second most common oncological disease in men, ranking just behind lung cancer (1). Many risk factors have been associated with PCa, such as race, family history and increasing age, with more than $60 \%$ of new cases being diagnosed in men aged between 60 and 70 years $(1,2)$. Additionally, sexually transmitted infections and dietary factors are also linked to the disease (2).

One of the most conventional methods for diagnosing PCa include prostatespecific antigen (PSA) testing, which is based on its concentration in blood serum (3). Despite being one of the most used, PSA testing is unspecific and false positive results are common, due to non-cancerous diseases such as benign prostatic hyperplasia (3). Once PCa is diagnosed, treatment options depend on the stage of the disease: when the tumor is clinically localized and of low-risk, patients may opt by active surveillance instead of radical interventions, such as prostatectomy $(4,5)$. However, more aggressive and/or metastatic tumors must be treated with hormonal therapy, radiation, chemotherapy and prostatectomy, that can lead to physical impairments, such as sexual and urinary dysfunction. The 5 -year survival rates are very optimistic (up to 100\%) for patients diagnosed at an early stage, however it declines to approximately $28 \%$ for patients diagnosed with late-stage cancer, so there is a need for new and effective therapeutic strategies (5).

An altered metabolism has been recognized as one the hallmarks of cancer (6). Metabolomics has been a valuable tool in the field of oncology, allowing the discovery of biochemical profiles and, therefore, of differences between healthy and cancer metabolic phenotypes (7). Since the metabolome reflects even slight changes that occur in the cell, metabolomics may allow for an early intervention because metabolic alterations are believed to precede any morphological alterations that might occur (810). Also, studying cancer metabolome may improve the knowledge on tumor behavior and help to develop new targeted therapeutic strategies, which are crucial for a good prognosis $(11,12)$.

In recent years, FTIR spectroscopy has emerged as a tool for metabolic profiling. This approach is based on the vibrations of the atoms in a molecule caused by the interaction of infrared (IR) radiation with matter (13-15). The molecular vibrations that result from this interaction are specific to the biochemical composition of the analyzed samples and lead to spectral differences between samples, producing a fingerprint of metabolism. FTIR spectroscopy is rapid, non-invasive and reagent-free, thus it is a suitable screening technique that may allow for the discrimination between healthy and cancer samples (16-19).

Regarding PCa, FTIR spectroscopy has been applied to tissue biopsies and cell lines, showing promising results and elucidating on biochemical alterations inherent to the disease $(11,20-22)$. Cell lines present certain advantages that validate their use in 
preliminary studies, such as the fact that they exhibit a defined cell state that allows the analysis of a target metabolic status. Also, they evade confounding factors characteristic of biofluids and tissues (for example, age, diet and gender) (23-25). Nonetheless, cell culture suffers for not being able to replicate cell-cell and cell-matrix interactions in the tumor microenvironment, which are vital for metabolic alterations that occur with tumor progression. Therefore, models that reproduce structure, function and metabolism of in vivo tumors should be considered for further validation of in vitro studies $(23,26)$.

The main objective of this study was to perform a FTIR spectroscopy study of a PCa cell line (22Rv1) and two normal prostate epithelial cell lines (PNT1A and PNT2) and identify spectral differences by principal component analysis (PCA). To the best of our knowledge, this work is the first to analyze 22Rv1 and PNT1A by FTIR spectroscopy.

\section{Material and Methods}

\subsection{Cell culture}

Prostate cancer (22Rv1) and normal prostate (PNT1A and PNT2) cell lines were cultured in RPMI-1640 culture media, supplemented with $10 \%$ FBS and 1\% penicillin/streptomycin mixture, and maintained in a humidified atmosphere at $37^{\circ} \mathrm{C}$ containing $5 \% \mathrm{CO}_{2}$. All the reagents used in this study were purchased from Thermo Fisher Scientific. PNT2 cell line was kindly given by Dr. Ricardo Perez-Tomás (University of Barcelona, Spain). 22Rv1 and PNT1A were a kind gift from Dr. Fátima Baltazar (University of Minho, Portugal). A detailed description of each cell line can be consulted in table 1.

\subsection{Preparation of cells}

After reaching around $90 \%$ of confluency, cells were prepared for FTIR analysis. To assess viability, cells were analyzed under the microscope. The culture medium was removed from each plate and cells were detached from the plate using a solution of trypsin $0,05 \%$ and EDTA $1 \%$. To stop the reaction, culture medium was added to the plates and the cell suspensions were transferred to separate tubes for centrifugation ( 3 minutes, $1000 \mathrm{rpm}$ ). Following centrifugation, the supernatant was discarded, and cells were resuspended in culture medium. Cells were counted using a TC20 ${ }^{\mathrm{TM}}$ Automated Cell Counter, from BIO-RAD, and a total of $10^{6}$ cells were used for each biological replicate. Cells were centrifuged for 3 minutes at $1000 \mathrm{rpm}$ to remove the medium and resuspended in phosphate-buffered saline (PBS). Washing cells with PBS is essential to remove residual medium and trypsin (27). PBS was removed by centrifugation ( 3 minutes, $1000 \mathrm{rpm}$ ) and cell pellets were kept on ice until FTIR analysis.

\subsection{FTIR measurements}

FTIR spectra were acquired in ATR mode in a FTIR spectrometer (Alpha Platinum ATR, Bruker), and processed using OPUS software ( ${ }^{\circ}$ Bruker). The spectra were obtained 
over the wavenumber range $4000-600 \mathrm{~cm}^{-1}$, with a resolution of $8 \mathrm{~cm}^{-1}$ and 64 coadded scans. Spectra acquisition was performed in a room with controlled temperature and relative humidity $\left(23^{\circ} \mathrm{C}\right.$ and $35 \%$, respectively). A background spectrum was acquired with the crystal empty before each different cell line and a total of 10 biological replicates for 22Rv1 and 8 for PNT1A and PNT2 were used. The cell pellet was placed on the crystal and spectra were obtained after the samples were completely air-dried. Between each measurement the crystal was cleaned with ethanol $70 \%$, followed by distilled water.

\subsection{FTIR data analysis}

All the raw spectra were normalized to the area of amide I band and the normalized spectra were derivatized, using the second derivative and Savitzky-Golay method with 3 smoothing points. Spectra were processed using The Unscrambler $X^{\circledR}$ software (v.10.4, CAMO, Oslo, Norway). The spectral regions $3000-2800 \mathrm{~cm}^{-1}, 1800$ $1500 \mathrm{~cm}^{-1}$ and $1500-900 \mathrm{~cm}^{-1}$ were chosen for analysis and all spectral assignments were made according to widely cited literature references.

\subsection{Multivariate analysis}

PCA was applied to the normalized second-derivative spectra of all the cell lines. For multivariate analysis, we used the spectral regions between $3000-2800 \mathrm{~cm}^{-1}, 1800$ $1500 \mathrm{~cm}^{-1}$ and $1500-900 \mathrm{~cm}^{-1}$. All the analyses were performed on The Unscrambler $X^{\circledR}$ software (v.10.4, CAMO, Oslo, Norway).

\section{Results}

\subsection{Overview of FTIR spectra}

Cell viability was confirmed by observation under the microscope, and each cell pellet consisted of mostly viable cells (unviable cells were discarded upon the removal of the culture medium before trypsinization of the cells from the plate). An area peak normalization was applied to ensure that the varying cell number between replicates would not affect the spectral variances, therefore highlighting differences in biochemical structure and not in absorbance intensity $(27,28)$.

\subsection{FTIR spectral interpretation}

A complete view of the averaged normalized spectra of each cell line, in the region between 4000 and $600 \mathrm{~cm}^{-1}$, can be observed in figure $1 \mathrm{~A}$. Briefly, in the 3000$2800 \mathrm{~cm}^{-1}$ region (figure 1B), bands at 2956 and $2871 \mathrm{~cm}^{-1}$ are assigned to the asymmetric and symmetric stretching of $\mathrm{CH}_{3}$ chains of lipids, respectively, whereas the bands at 2922 and $2851 \mathrm{~cm}^{-1}$ are attributed to the asymmetric and symmetric stretching of $\mathrm{CH}_{2}$ chains of lipids, respectively $(13,18,29,30)$. In the region between 1800 and 900 $\mathrm{cm}^{-1}$ (figure $1 \mathrm{C}$ ), the most prominent bands are associated with proteins: amide I (1640 $\left.\mathrm{cm}^{-1}\right)$ and amide II $\left(1540 \mathrm{~cm}^{-1}\right)$. The amide I band is attributed to $\mathrm{C}=\mathrm{O}$ and $\mathrm{C}-\mathrm{N}$ stretching 
of proteins, while the amide II band is assigned to $\mathrm{N}-\mathrm{H}, \mathrm{C}-\mathrm{N}$ and $\mathrm{C}-\mathrm{C}$ stretching. The amide I band is sensitive to the secondary structure of proteins and is frequently used for this type of analysis. The amide II band can also be used for studying the secondary structure of proteins, although to a lesser extent (30-34). Also, in this region, the band around $1740 \mathrm{~cm}^{-1}$ is assigned to the $\mathrm{C}=0$ stretching of phospholipid esters. In the $1500-900 \mathrm{~cm}^{-}$ 1 region, bands between 1480 and $1300 \mathrm{~cm}^{-1}$ are attributed to amino acid side chains and fatty acids and the major bands between 1300 and $900 \mathrm{~cm}^{-1}$ arise mainly due to carbohydrates (particularly glycogen) and phosphates associated with nucleic acids $(13,18,29,30)$.

\subsection{Principal Component Analysis}

Before PCA analysis, spectra were normalized using an area peak algorithm and a second-order derivative using Savitzky-Golay algorithm was performed to resolve overlapping peaks $(35,36)$. PCA allows to determine the most important sources of variability between prostate cancer and normal prostate cell lines. In this study, the spectral regions $3000-2800 \mathrm{~cm}^{-1}, 1800-1500 \mathrm{~cm}^{-1}$ and $1500-900 \mathrm{~cm}^{-1}$ were chosen for analysis.

PCA results for the $3000-2800 \mathrm{~cm}^{-1}$ range are presented in figure $2 \mathrm{~A}$. In the score plot, it is possible to observe that these cells are separated by principal component- 2 (PC2), and that 22Rv1 are in negative PC2, while PNT1A and PNT2 are in positive PC2. According to the loadings plot, 22Rv1 are mainly characterized by the spectroscopic signals located at 2917, 2874 and $2849 \mathrm{~cm}^{-1}$, while PNT1A and PNT2 are characterized by the peaks at 2925 and $2857 \mathrm{~cm}^{-1}$.

PCA of the spectral region between 1800 and $1500 \mathrm{~cm}^{-1}$ is illustrated in figure $2 \mathrm{~B}$. In this case, the discrimination between tumor and normal cells is provided by $\mathrm{PC}$ : 22Rv1 are in positive PC3, while PNT1A and PNT2 are located in negative PC3. The loadings plot indicates that the main sources of variability come from the $1700-1600 \mathrm{~cm}^{-}$ ${ }^{1}$ region. The main spectral assignments that characterize 22Rv1 are 1679, 1665, 1648, $1622 \mathrm{~cm}^{-1}$, and PNT1A and PNT2 are characterized by the peaks at 1653 and $1636 \mathrm{~cm}^{-1}$. In the $1500-900 \mathrm{~cm}^{-1}$ region, 22Rv1 are present in negative PC2, while PNT1A and PNT2 are located in the positive PC2. The main spectral assignments that characterize 22Rv1 are 1427, 1384, 1152, 1127, 1073, 1036, 1022 and $982 \mathrm{~cm}^{-1}$. PNT1A and PNT2 are characterized by the peaks 1240,1104, 1084, 1050 and $965 \mathrm{~cm}^{-1}$.

\section{Discussion}

Several studies have shown the potential of FTIR spectroscopy in distinguishing the metabolic profile of normal and cancer cells. This technique has been applied to cell lines derived from numerous types of neoplasms, such as breast $(28,37)$, cervix (38), colon $(39,40)$, gastric (41) and lung (42) cancers.

In this study, we have demonstrated the use of FTIR spectroscopy to differentiate between prostate cell lines derived from normal epithelium (PNT1A and PNT2) and 
primary prostate tumor (22Rv1). PCA clearly discriminated spectra from 22Rv1, and PNT1A and PNT2 in the $3000-2800 \mathrm{~cm}^{-1}, 1800-1500 \mathrm{~cm}^{-1}$ and $1500-900 \mathrm{~cm}^{-1}$ regions, indicating that they are biochemically different and, therefore, exhibit different metabolic profiles. In the spectral region from 3000 to $2800 \mathrm{~cm}^{-1}$, the main spectral assignments that allowed the separation of PNT1A and PNT2 are 2925 and $2857 \mathrm{~cm}^{-1}$, which arise, respectively, due to the asymmetric and symmetric stretching vibrations of $\mathrm{CH}_{2}$ chains of lipids. Furthermore, the bands at 2917 and $2849 \mathrm{~cm}^{-1}$, which were responsible for separating 22Rv1 from PNT1A and PNT2, can also be attributed to the asymmetric and symmetric stretching vibrations of $\mathrm{CH}_{2}$ chains of lipids. Because spectra were acquired with a resolution of $8 \mathrm{~cm}^{-1}$, the aforementioned peaks can be assigned to the same biochemical component. A shift to a lower frequency might suggest alterations in the lipid composition between normal and tumor cells, and an increase in disorder of the $\mathrm{CH}_{2}$ chains of membrane lipids have been associated with malignancy (17). Alterations in the membrane lipids have already been reported in prostate cancer tissue biopsies (21) and breast cancer-derived cell lines (37). Furthermore, alterations regarding lipid saturation have been detected in this spectral region. An increment in $\mathrm{CH}_{2} / \mathrm{CH}_{3}$ ratio suggests an increase in the length of fatty acid chains.

In the spectral region between 1800 and $1500 \mathrm{~cm}^{-1}$, the main assignments that are responsible for segregating 22Rv1 from PNT1A and PNT2 are 1758, 1679, 1665, 1648 and $1622 \mathrm{~cm}^{-1}$. The peak at $1758 \mathrm{~cm}^{-1}$ can be attributed to the $\mathrm{C}=\mathrm{O}$ stretching of lipid esters (43), suggesting a dysregulated lipid metabolism, which is known to be altered in cancer. In fact, an accumulation of cholesterol has been reported in PCa. Also, de novo lipid synthesis has been described in $\mathrm{PCa}$, which serves to produce fatty acids. Fatty acid synthesis plays an important role in cancer pathogenesis, and it is known that these newly synthesized fatty acids support cellular processes to promote cell proliferation and survival $(44,45)$. Additionally, de novo lipogenesis has been shown to promote saturation of membrane lipids, which has consequences in terms of membrane dynamics and uptake and efficacy of chemotherapeutics (46).

The amide I band $\left(1700-1600 \mathrm{~cm}^{-1}\right)$ arises due to the stretching vibrations of $C=0$ and $\mathrm{C}-\mathrm{N}$, and provides information about the secondary structure of proteins, which has been extensively investigated in several studies (31-33). The spectral assignments specific of this region that characterize $22 \mathrm{Rv} 1$ are $1679,1665,1648$ and $1622 \mathrm{~cm}^{-1}$. The frequency at $1679 \mathrm{~cm}^{-1}$ is assigned to antiparallel $\beta$-sheets, while 1665 and $1648 \mathrm{~cm}^{-1}$ are related to $\beta$-turns and unordered structures, respectively (47). Regarding the peak assigned to the antiparallel $\beta$-sheets, these structures are extremely present in less soluble proteins that are likely to form aggregates $(32,34)$. An increase in the relative amount of $\beta$-sheets, relative to $\alpha$-helical segments, has already been observed in colon adenocarcinoma cell lines (40). The peak at $1622 \mathrm{~cm}^{-1}$, however, can be specifically associated to the presence of protein aggregated strains $(32,48)$. Cancer cells are exposed to factors that induce stress and, therefore, disrupt proteostasis, causing protein misfolding and subsequent aggregation (49). Several tumors and cancer cell lines 
have been found to exhibit protein aggregation, mainly involving aggregates of tumor suppressor p53 (50-52), which can play an important role in carcinogenesis (53). Also, aggregation of $\mathrm{p} 53$ has been associated to platinum resistance and stem cell phenotype in a subset of ovarian cancer (54), which suggests a link between loss of proteostasis and cancer progression. On the other hand, the spectral assignments that characterize PNT1A and PNT2 are 1653 and $1636 \mathrm{~cm}^{-1}$, which are related to $\alpha$-helices and parallel $\beta$ sheets, respectively. $\alpha$-helices are usually present in more soluble proteins that are less likely to aggregate (34), and despite the presence of the assignment at $1636 \mathrm{~cm}^{-1}$ associated with $\beta$-sheets, this could be explained by the fact that most proteins exhibit a mixture of secondary structure (33).

A discrimination between tumor and normal cells was also observed in the spectral region between 1500 and $900 \mathrm{~cm}^{-1}$. The main assignments in the $1500-1300 \mathrm{~cm}^{-}$ ${ }^{1}$ range that characterize $22 \mathrm{Rv} 1$ are 1427 and $1384 \mathrm{~cm}^{-1}$, the former being associated with the $\mathrm{CH}_{3}$ and $\mathrm{CH}_{2}$ deformation vibrations mostly due to lipid contribution, and the latter with the $\mathrm{CH}_{3}$ symmetric wagging of phospholipids, fatty acids and triglycerides $(38,55)$. These results may confirm the lipid alterations that were detected in other regions of the spectrum. The bands between 1460 and $1400 \mathrm{~cm}^{-1}$ arise due to lipid contribution, and some have been explored in previous studies. For instance, the uterine cervical adenocarcinoma cell line SiSo, along with exfoliated cervical cells and cervical adenocarcinoma tissue, exhibit an increased intensity and a shift to a lower frequency of the band at $1400 \mathrm{~cm}^{-1}$, which might indicate structural changes of the $\mathrm{CH}_{2}$ chains of lipids (38).

The bands present in the region between 1300 and $900 \mathrm{~cm}^{-1}$ arise mainly due to carbohydrates and phosphates associated with nucleic acids. The most important spectral assignments characteristic of $22 \mathrm{Rv} 1$ are $1152,1127,1073,1036,1022 \mathrm{~cm}^{-1}$. The bands at 1152 and $1022 \mathrm{~cm}^{-1}$ are related to carbohydrates, particularly glycogen (which is specifically assigned to the frequency $1022 \mathrm{~cm}^{-1}$ ). A reduced glycogen content has been observed in PCa tissue biopsies (21), and cervical adenocarcinoma tissue and cervical adenocarcinoma cells (38). The decrease in glycogen content in malignant cells can be attributed to their higher metabolic activity and, thus, an increase in glycolysis $(11,17,38,56)$. The remaining bands $\left(1127,1073\right.$ and $\left.1036 \mathrm{~cm}^{-1}\right)$ account for differences associated with nucleic acids. This could be linked to the fact that nucleic acids exhibit increased hydrogen-bonding of the phosphodiester groups and a higher level of packing in cancer cells, as confirmed by several studies (40).

In this study FTIR spectroscopy and PCA were successfully applied to a PCa and two normal prostate (PNT1A and PNT2) cell lines. Our results clearly indicate that this technique, coupled with multivariate analysis, can be used to distinguish the different types of prostate cells in several spectral regions. However, in order to validate our results, other biological samples should be considered for analysis, such as human urine, serum/plasma and prostatic fluid (57). Also, because FTIR spectroscopy is uncapable of detecting specific metabolites that are responsible for causing changes, other 
metabolomic techniques should be considered, such as mass spectrometry and nuclear magnetic resonance. Prostate cancer metabolome has been studied by these techniques, allowing the identification of metabolites implicated in certain metabolic pathways (58-61). Nevertheless, our results indicate that primary tumor cells can be distinguished from normal cells, and that lipid metabolism obviously plays an important role in tumorigenesis. Other alterations, such as protein aggregation, can also be an important event in cancer progression. Given the fact that the biochemical composition of the prostate cell lines can be detected by FTIR, it could be useful in providing insights on new targets for more accurate and sensitive therapeutic strategies.

\section{Funding}

This work was supported by Fundação para a Ciência e a Tecnologia, FEDER and COMPETE (grants number UID/BIM/04501/2013, POCI-01-0145-FEDER-007628, POCI01-0145-FEDER-016728 and PTDC/DTP-DES/6077/2014). SM, MCH and IV are also funded with individuals grant of Fundação para a Ciência e Tecnologia I.P. (SFRH/BD/131820/2017, SFRH/BD/131846/2017 and SFRH/BD/101942/2014, respectively).

\section{References}

1. Ferlay J, Soerjomataram I, Dikshit R, Eser S, Mathers C, Rebelo M, et al. Cancer incidence and mortality worldwide: Sources, methods and major patterns in GLOBOCAN 2012. Int J Cancer. 2015;136(5):E359-86.

2. Nelson WG, De Marzo AM, Isaacs WB. Prostate Cancer. N Engl J Med. 2003;349(4):366-81.

3. Kellokumpu-Lehtinen $\mathrm{P}$, Nurmi M, Koskinen $\mathrm{P}$, Irjala K. Prostate-specific antigen as a marker of adenocarcinoma of prostate. Urol Res. 1989;17(4):245-9.

4. Winoker JS, Anastos H, Rastinehad AR. Targeted Ablative Therapies for Prostate Cancer. In: Daneshmand S, Chan KG, editors. Genitourinary Cancers. Cham: Springer International Publishing; 2018. p. 15-53.

5. Miller KD, Siegel RL, Lin CC, Mariotto AB, Kramer JL, Rowland JH, et al. Cancer treatment and survivorship statistics, 2016. CA Cancer J Clin. 2016 Jul;66(4):271-89.

6. Hanahan D, Weinberg RA. Hallmarks of cancer: The next generation. Cell. 2011;144(5):646-74.

7. Aboud OA, Weiss RH. New opportunities from the cancer metabolome. Clin Chem. 2013;59(1):138-46.

8. Zhang A, Yan G, Han Y, Wang X. Metabolomics approaches and applications in prostate cancer research. Appl Biochem Biotechnol. 2014;174(1):6-12.

9. Vermeersch KA, Styczynksi MP. Applications of Metabolomics in Cancer Studies. J Carcinog. 2013;12(9):1-9.

10. Roberts MJ, Schirra HJ, Lavin MF, Gardiner RA. Metabolomics: A novel approach to early and noninvasive prostate cancer detection. Korean J Urol. 2011;52(2):79-89.

11. Gazi E, Dwyer J, Gardner P, Ghanbari-Siahkali A, Wade AP, Miyan J, et al. Applications of Fourier transform infrared microspectroscopy in studies of benign prostate and prostate cancer. A pilot study. J Pathol. 2003;201(1):99-108.

12. Eidelman E, Twum-Ampofo J, Ansari J, Siddiqui MM. The Metabolic Phenotype of Prostate Cancer. Front Oncol. 2017;7:1-6.

13. Ellis DI, Dunn WB, Griffin JL, Allwood JW, Goodacre R. Metabolic fingerprinting as a diagnostic tool. Pharmacogenomics. 2007;8(9):1243-66.

14. Olsztynska-Janus S, Szymborska-Malek K, Gasior-Glogowska M, Walski T, Komorowska M, Witkeiwicz W, et al. Spectroscopic techniques in the study of human tissues and their components. Part I: IR spectroscopy. Acta Bioeng Biomech. 2012;14(3):101-15.

15. Stuart BH. Infrared Spectroscopy Of Biological Applications: An Overview. Encycl Anal Chem. 
2012;529-58.

16. Kendall C, Isabelle M, Bazant-Hegemark F, Hutchings J, Orr L, Babrah J, et al. Vibrational Spectroscopy: A Clinical Tool For Cancer Diagnostics. Analyst. 2009;134(6):1029-45.

17. Othman NH, El-tawil SG. FTIR Spectroscopy : A New Technique In Cancer Diagnoses. US Chinese J Lymphology Oncol. 2009;8(1):10-4.

18. Stuart BH. Infrared Spectroscopy: Fundamentals and Applications. Vol. 8, Methods. 2004. 224 p.

19. Griffin JL, Shockcor JP. Metabolic profiles of cancer cells. Nat Rev Cancer. 2004;4(7):551-61.

20. Harvey TJ, Gazi E, Henderson A, Snook RD, Clarke NW, Brown M, et al. Factors influencing the discrimination and classification of prostate cancer cell lines by FTIR microspectroscopy. Analyst. 2009;134(6):1083-91.

21. Felgueiras J, Vieira Silva J, Nunes A, Patrício A, Pelech S, Fardilha M. Understanding prostate cancer biology using metabolomics and proteomics approaches: potentials in the improvement of the diagnosis, prognosis and identification of new therapeutic targets. Eur J Cancer. 2018 Feb 9;72:S192.

22. Harvey TJ, Henderson A, Gazi E, Clarke NW, Brown M, Faria EC, et al. Discrimination of prostate cancer cells by reflection mode FTIR photoacoustic spectroscopy. Analyst. 2007;132(4):292.

23. Halama A. Metabolomics in cell culture - A strategy to study crucial metabolic pathways in cancer development and the response to treatment. Arch Biochem Biophys. 2014;564:100-9.

24. Zhang A, Sun H, Xu H, Qiu S, Wang X. Cell Metabolomics. Omi A J Integr Biol. 2013;17(10):495501.

25. Čuperlović-Culf M, Barnett DA, Culf AS, Chute I. Cell culture metabolomics: Applications and future directions. Drug Discov Today. 2010;15(15-16):610-21.

26. Keshari KR, Sriram R, Criekinge M Van, Wilson DM, Zhen J, Vigneron DB, et al. Metabolic Reprogramming and Validation of Hyperpolarized 13C Lactate as a Prostate Cancer Biomarker Using a Human Prostate Tissue Slice Culture Bioreactor. 2014;73(11):1171-81.

27. Baker MJ, Trevisan J, Bassan P, Bhargava R, Butler HJ, Dorling KM, et al. Using Fourier transform IR spectroscopy to analyze biological materials. Nat Protoc. 2014;9(8):1771-91.

28. Mostaço-Guidolin LB, Murakami LS, Batistuti MR, Nomizo A, Bachmann L. Molecular and chemical characterization by Fourier transform infrared spectroscopy of human breast cancer cells with estrogen receptor expressed and not expressed. Spectroscopy. 2010;24(5):501-10.

29. Naumann D. FT-Infrared And FT-Raman Spectroscopy In Biomedical Research. Appl Spectrosc Rev. 2001;36(2-3):239-98.

30. Santos F, Magalhães S, Henriques MC, Fardilha M, Nunes A. Spectroscopic features of cancer cells: FTIR spectroscopy as a tool for early diagnosis. Curr Metabolomics. 2018;6(2).

31. Magalhães S, Graça A, Tavares J, Santos MAS, Delgadillo I, Nunes A. Saccharomyces cerevisiae as a Model to Confirm the Ability of FTIR to Evaluate the Presence of Protein Aggregates. Spectr Anal Rev. 2018;06(01):1-11.

32. Shivu B, Seshadri S, Li J, Oberg KA, Uversky VN, Fink AL. Distinct $\beta$-sheet structure in protein aggregates determined by ATR-FTIR spectroscopy. Biochemistry. 2013;52(31):5176-83.

33. Miller LM, Bourassa MW, Smith RJ. FTIR Spectroscopic Imaging Of Protein Aggregation In Living Cells. Biochim Biophys Acta. 2013;1828(10):2339-46.

34. Barth A, Zscherp C. What vibrations tell about proteins. Q Rev Biophys. 2002;35(04):369-430.

35. Denbigh JL, Perez-Guaita D, Vernooij RR, Tobin MJ, Bambery KR, Xu Y, et al. Probing the action of a novel anti-leukaemic drug therapy at the single cell level using modern vibrational spectroscopy techniques. Sci Rep. 2017;7(1):1-12.

36. Ricciardi V, Portaccio M, Piccolella S, Manti L, Pacifico S, Lepore M. Study of SH-SY5Y cancer cell response to treatment with polyphenol extracts using FT-IR spectroscopy. Biosensors. 2017;7(4):1-16.

37. Hwang EJ, Lee SK, Kwak YH, Park SS, Hong SM. Live cells detection in breast cell-line by FTIR microspectrometer. In: Proceedings of IEEE Sensors. 2008. p. 878-81.

38. Neviliappan S, Fang Kan L, Tiang Lee Walter T, Arulkumaran S, Wong PTT. Infrared spectral features of exfoliated cervical cells, cervical adenocarcinoma tissue, and an adenocarcinoma cell line (SiSo). Gynecol Oncol. 2002;85(1):170-4.

39. Rigas B, Morgello S, Goldman IS, Wong PT. Human colorectal cancers display abnormal Fouriertransform infrared spectra. Proc Natl Acad Sci U S A. 1990;87(20):8140-4.

40. Rigas B, Wong PTT. Human Colon Adenocarcinoma Cell Lines Display Infrared Spectroscopic Features of Malignant Colon Tissues. Cancer Res. 1992;52(1):84-8. 
41. Fujioka N, Morimoto $\mathrm{Y}$, Arai T, Takeuchi K, Yoshioka M, Kikuchi M. Differences between infrared spectra of normal and neoplastic human gastric cells. Spectroscopy. 2004;18(1):59-66.

42. Lee SY, Yoon KA, Jang SH, Ganbold EO, Uuriintuya D, Shin SM, et al. Infrared spectroscopy characterization of normal and lung cancer cells originated from epithelium. J Vet Sci. 2009;10(4):299-304.

43. Wehbe K, Pineau R, Eimer S, Vital A, Loiseau H, Déléris G. Differentiation between normal and tumor vasculature of animal and human glioma by FTIR imaging. Analyst. 2010;135(12):3052-9.

44. Griffin JE. Androgen Resistance - The Clinical and Molecular Spectrum. N Engl J Med. 1992;326(9):611-8.

45. Menendez JA, Lupu R. Fatty acid synthase and the lipogenic phenotype in cancer pathogenesis. Nat Rev Cancer. 2007;7(10):763-77.

46. Rysman E, Brusselmans K, Scheys K, Timmermans L, Derua R, Munck S, et al. De novo lipogenesis protects cancer cells from free radicals and chemotherapeutics by promoting membrane lipid saturation. Cancer Res. 2010;70(20):8117-26.

47. Talari ACS, Martinez MAG, Movasaghi Z, Rehman S, Rehman IU. Advances in Fourier transform infrared (FTIR) spectroscopy of biological tissues. Appl Spectrosc Rev. 2017;52(5):456-506.

48. Kumar S, Srinivasan A, Nikolajeff F. Role of infrared spectroscopy and imaging in cancer diagnosis. Curr Med Chem. 2017;24(May).

49. Hetz C, Chevet E, Oakes SA. Proteostasis control by the unfolded protein response. Nat Cell Biol. 2015;17(7):829-38.

50. Koo EH, Lansbury PT, Kelly JW. Amyloid diseases: Abnormal protein aggregation in neurodegeneration. Proc Natl Acad Sci. 1999;96(18):9989-90.

51. Levy CB, Stumbo AC, Ano Bom APD, Portari EA, Carneiro Y, Silva JL, et al. Co-localization of mutant p53 and amyloid-like protein aggregates in breast tumors. Int J Biochem Cell Biol. 2011;43(1):604.

52. Xu J, Reumers J, Couceiro JR, De Smet F, Gallardo R, Rudyak S, et al. Gain of function of mutant p53 by coaggregation with multiple tumor suppressors. Nat Chem Biol. 2011;7(5):285-95.

53. Yang-Hartwich Y, Bingham J, Garofalo F, Alvero AB, Mor G. Detection of p53 Protein Aggregation in Cancer Cell Lines and Tumor Samples. In: Apoptosis and Cancer: Methods and Protocols. 2015. p. 75-86.

54. Yang-Hartwich Y, Soteras MG, Lin ZP, Holmberg J, Sumi N, Craveiro V, et al. P53 Protein Aggregation Promotes Platinum Resistance in Ovarian Cancer. Oncogene. 2014;34(27):3605-16.

55. Bellisola G, Sorio C. Infrared Spectroscopy And Microscopy In Cancer Research And Diagnosis. Am J Cancer Res. 2012;2(1):1-21.

56. Clemens G, Hands JR, Dorling KM, Baker MJ. Vibrational spectroscopic methods for cytology and cellular research. Analyst. 2014 Sep;139(18):4411-44.

57. Lima AR, Bastos M de L, Carvalho M, Guedes de Pinho P. Biomarker discovery in human prostate cancer: An update in metabolomics studies. Transl Oncol. 2016;9(4):357-70.

58. Mondul AM, Moore SC, Weinstein SJ, Männistö S, Sampson JN, Albanes D. 1-Stearoylglycerol is associated with risk of prostate cancer: results from a serum metabolomic profiling analysis. Metabolomics. 2014 Oct;10(5):1036-41.

59. Giskeødegård GF, Bertilsson H, Selnæs KM, Wright AJ, Bathen TF, Viset T, et al. Spermine and Citrate as Metabolic Biomarkers for Assessing Prostate Cancer Aggressiveness. Monleon D, editor. PLoS One. 2013 Apr;8(4):e62375.

60. Khan AP, Rajendiran TM, Bushra A, Asangani IA, Athanikar JN, Yocum AK, et al. The Role of Sarcosine Metabolism in Prostate Cancer Progression. Neoplasia. 2013;15(5):491-IN13.

61. Sreekumar A, Poisson LM, Rajendiran TM, Khan AP, Cao Q, Yu J, et al. Metabolomic profiles delineate potential role for sarcosine in prostate cancer progression. Nature. 2009;457(7231):910-4.

62. Berthon P, Cussenot O, Hopwood L, Le Duc A, Maitland NJ. Functional expression of SV40 in normal human prostatic epithelial and fibroblastic cells: Differentiation pattern of nontumorigenic cell lines. Int J Oncol. 1995;6(2):333-43.

63. Sramkoski RM, Pretlow TG, Giaconia JM, Pretlow TP, Schwartz S, Sy MS, et al. A new human prostate carcinoma cell line, 22Rv1. In Vitro Cell Dev Biol Anim. 1999;35(August):403-9.

64. van Bokhoven A, Varella-Garcia M, Korch C, Johannes WU, Smith EE, Miller HL, et al. Molecular characterization of human prostate carcinoma cell lines. Prostate. 2003;57(3):205-25. 


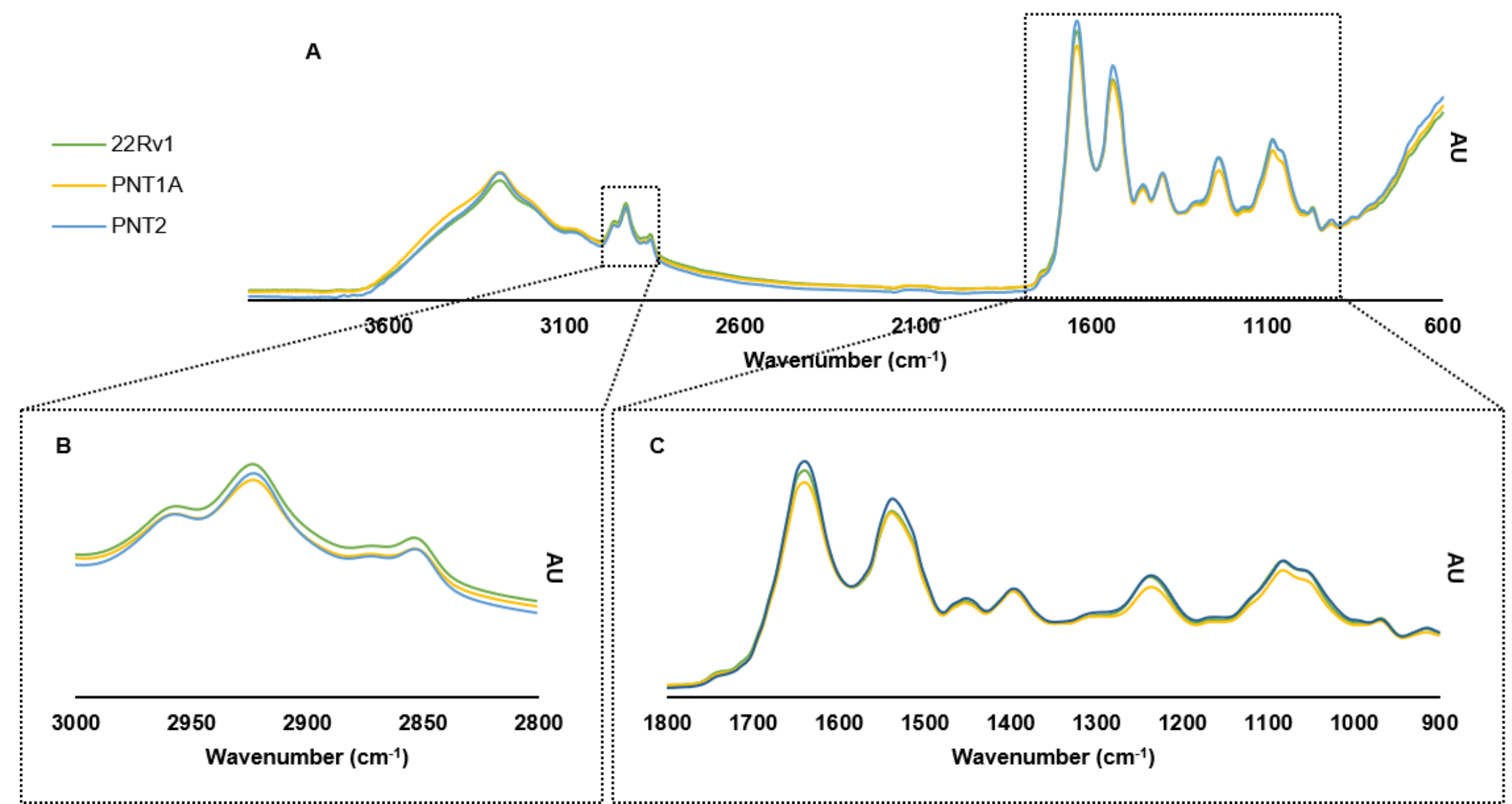

Figure 1: Normalized mean spectra of prostate cancer (22Rv1) and normal prostate (PNT1A and PNT2) cells in the $4000-600 \mathrm{~cm}^{-1}$ region (A); Amplification of the regions between 3000 and $2800 \mathrm{~cm}^{-1}$, and 1800 and $900 \mathrm{~cm}^{-1}$. X-axis: wavenumber $\left(\mathrm{cm}^{-1}\right)$; Y-axis: arbitrary units (AU). 

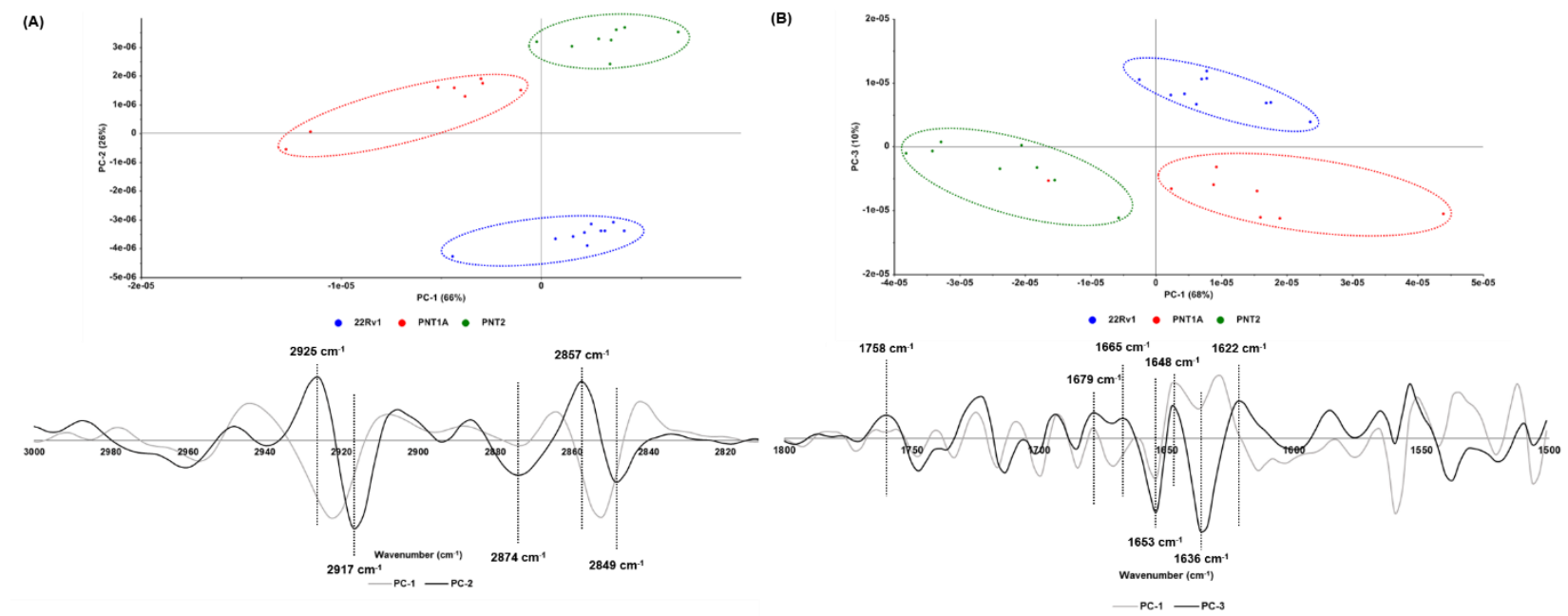

(c)
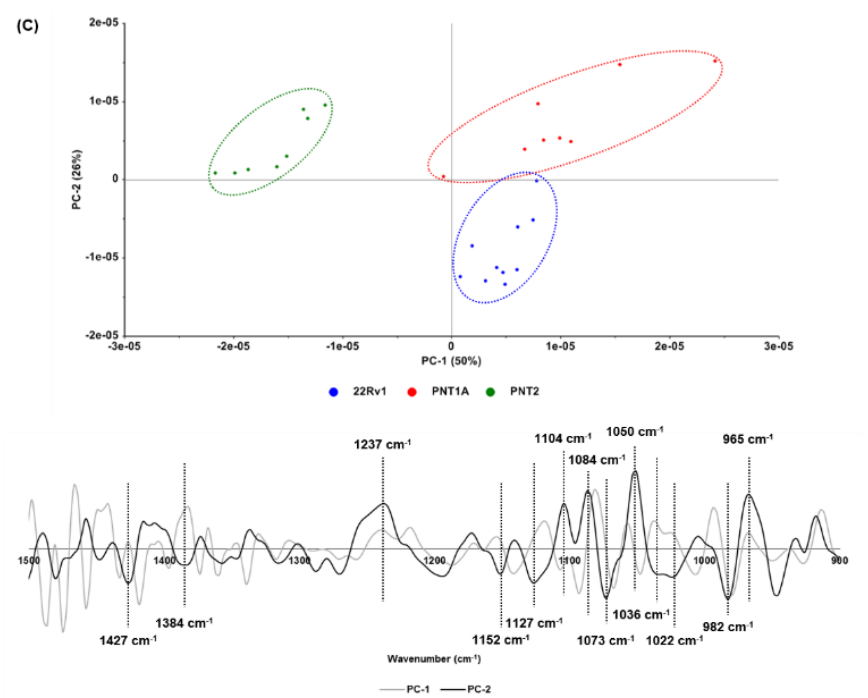

Figure 2: PCA score and loadings plots from the normalized second derivative spectra of prostate cancer (22Rv1) and normal prostate (PNT1A and PNT2) cell lines on the $3000-2800 \mathrm{~cm}^{-1}(\mathrm{~A}), 1800-1500 \mathrm{~cm}^{-1}(\mathrm{~B})$ and $1500-900 \mathrm{~cm}^{-1}(\mathrm{C})$ regions. 
Table 1: Main characteristics of the prostate cell lines

\begin{tabular}{|c|c|c|c|c|c|c|}
\hline Cell line & DERIVATION & MORPHOLOGY & AR PROTEIN & DISEASE & TUMORIGENIC & REFERENCES \\
\hline PNT1A & $\begin{array}{l}\text { Normal prostate } \\
\text { epithelial cells } \\
\text { immortalized with } \\
\text { SV40 genome }\end{array}$ & Epithelial & Yes & Healthy & No & $(62)$ \\
\hline PNT2 & $\begin{array}{c}\text { Normal prostate } \\
\text { epithelial cells } \\
\text { immortalized with } \\
\text { SV40 genome }\end{array}$ & Epithelial & Yes & Healthy & No & $(62)$ \\
\hline 22Rv1 & $\begin{array}{c}\text { Primary tumor } \\
\text { (established from } \\
\text { xenograft } \\
\text { CWR22R) }\end{array}$ & Epithelial & Yes & Carcinoma & Yes & $(63,64)$ \\
\hline
\end{tabular}

